\title{
GEOMETRIA FRACTAL DOS VEIOS DE QUARTZO DA SERRA DE OURO PRETO, FLANCO SUDESTE DO ANTICLINAL DE MARIANA, QUADRILÁTERO FERRÍFERO/MG
}

\section{CLÁUDIO M. TEIXEIRA DA SILVA ${ }^{1}$, MARCO A. FONSECA ${ }^{1} \&$ ADILSON R. DA COSTA ${ }^{2}$}

\begin{abstract}
RESUMO São apresentados os resultados do estudo, com aplicaçâo da Geometria Fractal, dos sistemas de veios de quartzo que ocorrem na serra de Ouro Preto, que corresponde ao flanco sudeste do Anticlinal de Mariana, Quadrilátero Ferrífero. A Geometria Fractal foi usada para caracterizar o fator de forma dos veios e sua aplicação contribuiu para o entendimento dos processos geradores dos mesmos e de sua inserção na evolução regional. Foram analisadas três seções, com 4km de extensão total, ao longo do trend da estrutura.

613 veios foram cartografados em superfície e subsuperfície (galerias subterrâneas), com medidas de espessura, largura, espaçamento e comprimento. 161 veios encontravam-se alojados $\mathrm{em}$ quartzito, $60 \mathrm{~cm}$ filito e $392 \mathrm{~cm}$ itabirito. Os valores obtidos foram lançados em gráficos log$\log$ de regressão linear (gráficos acumulativos de número de veios versus espessura, número de veios versus comprimento e número de veios versus espaçamento), com ajuste potencial de linha (best fit), que permitiram a obtenção das dimensões fractais dos veios, por diferentes tipos de rocha encaixante.

Dois sistemas de veios, sendo um mais antigo, de caráter concordante ou sub-concordante à foliação regional, e que foi gerado em evento extensional. Os veios desse sistema são cataclasados e sacaroidais, tendo sido deformados por evento contracional posterior. O outro sistema engloba veios mais novos, discordantes, e que possuem trama cristalina, tendo sido gerados na fase final de evento contracional posterior: Nesse sistema estão os veios de maiores dimensões, sendo que os mesmos cortam as camadas de quartzitos e têm maior relação axial do que aqueles que cortam as formações ferríferas e filitos.

Por meio da análise fractal verifica-se que os fatores de forma indicam maiores valores das dimensōes fractais dos veios em sentido leste, o que se traduz em veios com morfologia achatada ou "planar" a oeste. Para leste, esta morfologia planar da lugar a uma morfologia "nodular". Por outro lado, a análise fractal da densidade dos sistemas de veios mostra que os valores de densidade aumentam no sentido leste, para ambos os sistemas. Verifica-se, ainda, que os maiores valores de densidade estão relacionados aos sistemas de veios com maior dimensão fractal. Do ponto de vista geológico, estes dados podem indicar uma proximidade maior das fontes de fluidos junto à zona periclinal do Anticlinal de Mariana e/ou magnitudes de deformação associadas ao evento contracional crescentes em direção a leste, o que vem confirmar os dados geológicos regionais.
\end{abstract}

Palavras-chaves: geometria fractal, veios de quatrzo, Anticlinal de Mariana

ABSTRACT FRACTAL GEOMETRY OF QUARTZ VEINS OF THE SERRA DE OURO NEGRO, SOUTHEASTERN FLANK OF THE MARIANA ANTICILINE, IRON QUADRANGLE, MINAS GERAIS Fractal analysis statistics combined with textural and structural data of quartz vein sets have been used to address their cvolution in the tectonic context of the Ouro Preto Range, which is the southern limb of the Mariana Anticline. Fractal statistics have become a convenient way to deal with the problem of the scale analysis of vein sets considering that vein dimensions (length, thickness and spacing) have analogous relationships and length and thickness vary according to a power law distribution.

The vein sets have been mapped in three sections across the Ouro Preto Range, $2 \mathrm{~km}$ from each other. 613 veins have been mapped on the surface and in abandoned mine galleries. Measured data comprise thickness, length and spacing. 161 veins are hosted in quartzite, 60 in phyllite and 392 in the iron formation (BIF). Data have been plotted in cumulative log-plots of number of veins versus thickness, number of veins versus length, thickness versus length and number of veins versus spacing.

The older vein sets are parallel or subparallel to the regional cleavage. These veins underwent dynamic recrystalization and have been formed as a consequence of an extensional event. The younger vein set displays a crystalline fabric not truncated by the regional cleavage. The largest veins cross the quartzite layers and have larger axial ratios than the smaller ones that cross the phyllite and iron formation.

Analysis of shape factors (thickness and length) using the fractal dimension D revealed that both vein sets display a flat shape (prolate in section) in the western portion of the studied area changing to a nodule shape (oblate in section) towards the east. In addition, vein density is greater for larger values of D and D increases eastward for both sets of veins. These data may suggest that the source of the fluids is closer to the axis of the Mariana Anticline and/or that contractional strain increases towards the east as reported by regional geology data.

Keywords: Fractal geometry, guartz veins, Mariana Anticlinal.

INTRODUÇĀO Diversos trabalhos de análise estrutural têm sido recentemente realizados nas estruturas que encerram a mineralização filoneana da serra de Ouro Preto. Boa parte destes abordou a questão dos sistemas de veios aí alojados, não tanto pelo seu aspecto econômico, mas pelo significado estrutural, como marcadores da evolução tectônica daquele segmento do Quadrilátero Ferrífero. Entre tais trabalhos, podem ser destacados os Nalini Jr. (1993) e Cavalcanti (1999), nos quais as abordagens adotadas seguiram o método clássico de análise estrutural, ou seja, a identificação de famílias de estruturas com base em parâmetros geométricos e de trama, a determinação de critérios de superposição e de cruzamento estrutural, entre outros. Análises de quantificação da deformação, por outro lado, inexistem, fato facilmente explicado pela ausência, tanto nas encaixantes, como nos corpos, de elementos que se prestem à avaliação quantitativa.

Em função desta dificuldade, neste trabalho é aplicada uma nova metodologia para a análise dos sistemas filoneanos, a Geometria Fractal. Esta ferramenta tem sido cada vez mais utilizada, a partir de sua explicitação por Mandelbrot (1983), não só em geociências e es- pecificamente para análise de sistemas filoneanos, como também em diversas outras áreas do conhecimento. Essencialmente, a Geometria Fractal disponibiliza uma metodologia que permite a análise de fatores de forma de quaisquer elementos que, em determinada escala, apresentem dado ordenamento geométrico das partes que o compõem. Tendo por base um balizamento geológico adquirido através das pesquisas citadas anteriormente, o trabalho, portanto, se apresenta como uma forma de teste da metodologia, no sentido de verificar se os resultados obtidos, a partir da análise fractal, são compatíveis com aqueles obtidos através do método geológico clássico. Por outro lado, o teste é significativo, pois ele pode ser generalizado, caso os resultados se mostrem compatíveis, para áreas onde os critérios geológicos não sejam suficientes ou seguros para elucidar questões acerca dos modelos evolutivos. Outro aspecto relevante é que se pode, através da metodologia dos fractais, exercitar a capacidade de previsão, seja através da extensão ou projeção de trends, seja através das tendências que sejam eventualmente determinadas. 
Diversos trabalhos que abordaram a evolução de veios ou sistemas de veios, usando essa metodologia, têm sido apresentados recentemente na literatura, dentre estes destacam-se os de Manning (1994), Sanderson et al. (1994), Brooks (1994), Clarck et al. (1995), McCaffrey e Johnston (1996), Johnston e McCaffrey (1996), Jébrak (1997) e Hippertt e Massucato (1998).

LOCALIZAÇÃO DA ÁREA E MÉTODOS DE TRABALHO $A$ área estudada localiza-se na serra de Ouro Preto (Figura 1), parte norte da cidade de Ouro Preto, englobando uma faixa leste-oeste que vai desde o Bairro Taquaral ao Bairro São Cristóvão (Veloso), numa extensão de $4 \mathrm{~km}$. Três subáreas foram analisadas em detalhe: os bairros São Cristóvão (Veloso), Lajes e Piedade/Taquaral. Os locais estudados (afloramentos naturais, cortes) são acessados por ruas da própria malha urbana. Porém, boa parte das exposições encontra-se em minas e galerias subterrâneas antigas.

A metodologia dos trabalhos compreendeu a cartografia dos sistemas de veios de quartzo, envolvendo medições de espessura, largura, espaçamento e orientação, em três dimensões. Os dados obtidos foram então tratados estatisticamente em gráficos log-log para a determinação da dimensão fractal dos veios, tratamento este feito de duas manei- ras: uma de caráter mais genérico e também por classes, em função da rocha hospedeira, modo de ocorrência e a outra por "famílias" ou sets de veios.

Os dados coletados em superfícic referem-se às áreas aflorantes do quartzito da Formação Moeda. Os veios de quartzo que aí se encontram foram medidos e plotados em base cartográfica e/ou ortofotos. As medições executadas referem-se à espessura, ao comprimento aflorante, ao afastamento entre veios e à atitude. Os dados para os itabiritos da Formação Cauê e filitos da Formação Batatal foram obtidos $\mathrm{cm}$ galerias subterrâneas situadas próximas às áreas aflorantes dos quartzitos.

Os veios receberam uma codificação funcional baseada na rocha encaixante $(\mathrm{Q}=$ quartzito, $\mathrm{I}=$ itabirito, $\mathrm{F}=$ filito) e na relação espacial que estabelecem com a rocha $(\mathrm{D}=$ discordante, $\mathrm{I}=$ inclinado, $\mathrm{V}=\mathrm{ver}$ tical a subvertical e $\mathrm{C}=$ concordante). Por exemplo, um veio QDV significa um veio encaixado no quartzito de maneira discordante com a foliação, em posição vertical ou subvertical; um veio ICI significa um veio encaixado em itabiritos de mancira concordante com a loliação, portanto inclinado como esta. Os resultados foram tabelados e tratados estatisticamente através do programa Excel com utilização de análise de regressão $\mathrm{cm}$ gráficos de dispersão $\log$ - $\log$.

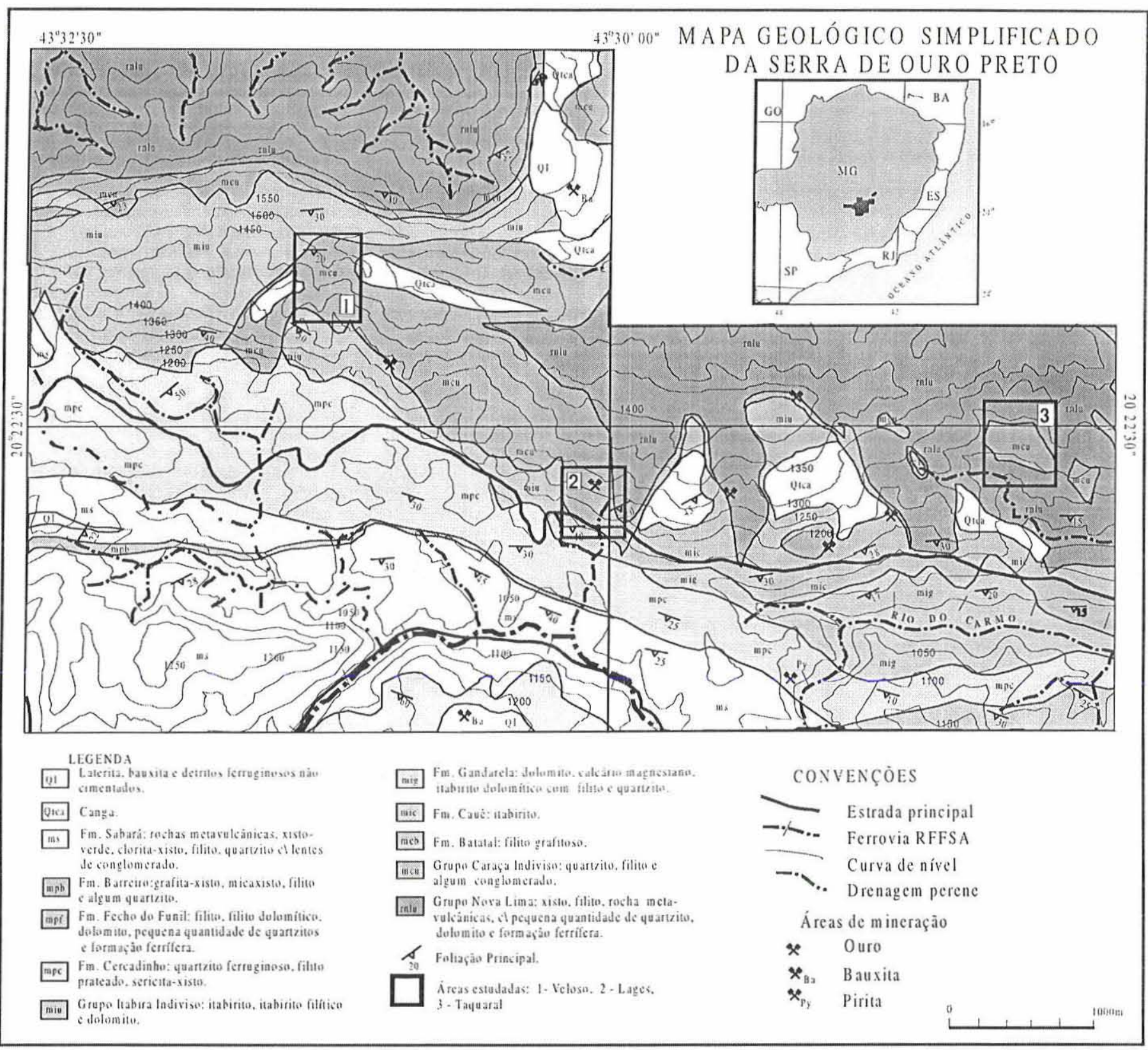

Figura I- Mapa simplificado da regiño da serra de Ouro Preto. Compilado de Barbosa (1969). Áreas trabalhadas: I - Veloso. 2 - Lajes. 3 - Taquaral. 
GEOLOGIA A serra de Ouro Preto localizada na parte sudeste do Quadrilátero Ferrífero, compreende uma unidade morfológica delineada por sequêencias supracrustais de idade paleoproterozóica. A seqüência estratigráfica do Quadrilátero Ferrífero envolve terrenos de alto grau metamórfico, de idade arqueana, inseridos nos complexos do embasamento, seqüências vulcano-sedimentares arqueanas do tipo greenstone belt, relacionadas ao Supergrupo Rio das Velhas e seqüências metassedimentares plataformais, de idade Paleoproterozóica, englobadas no Supergrupo Minas.

Estruturalmente, a Serra de Ouro Preto tem direção E-W e se constitui no flanco sul do Anticlinal de Mariana (Figura 1), que corresponde a uma dobra aberta, normal, com eixo caindo suavemente para sudeste. As rochas mergulham para o sul com valores $\mathrm{cm}$ torno de 20 a $30^{\circ}$ e o seu relevo é sustentado pelos itabiritos e por quartzitos da Formação Moeda. A serra de Ouro Preto ocorre ao longo de uma zona de cisalhamento oblíqua dextral, considerada como parte do Sistema de Cisalhamento Fundão-Cambotas (Endo e Fonseca 1992).

Do ponto de vista litoestratigráfico, as litologias que compōem a serra de Ouro Preto pertencem aos Grupos Nova Lima, Caraça c Itabira.

Os xistos do Grupo Nova Lima (Rnl) aparecem sempre muito alterados. Em superfície, são normalmente argilosos nas colorações vermelha, rósea e amarelada. Devido às poucas e más exposições em superfície e subsuperfície, não foram tratados os veios encontrados nessa unidade.

O Grupo Caraça (Mc) compōe-se das Formações Moeda (Mcm) c Batatal (Mcb).Os quartzitos da Formação Mocda estão milonitizados $\mathrm{c}$ intensamente fraturados. Os quartzitos podem aparecer frescos ou alterados. Quando alterados, são friáveis, de cor cinza-esbranquiçada e micáceos, com intercalações milimétricas de filito cinza-prateado. Quando inalterados, apresentam-se compactos c com aspecto silicificado. Em lâminas delgadas, tais quartzitos apresentam-se com estruturas miloníticas e texturas granoblásticas lenticulares, caracterizando os micrólitons, e texturas lepidoblásticas no domínio das clivagens. São evidentes os processos de transferência de massa por dissolução ("solution transfer").

Os filitos da Formação Batatal (Mcb) apresentam normalmente coloração cinza (média a escura), são grafitosos, sericíticos e macios ao tato. Em superfícic, os afloramentos dessa formação estão normalmente muito alterados e são comumente raros, devido à cobertura vegetal.

O Grupo Ittabira está representado pelos itabiritos da Formação Cauê (Mic). As rochas apresentam alternância de níveis milimétricos de quartzo e de hematita (óxido de ferro). Apresentam, em alguns níveis, pequenas dobras assimétricas, centimétricas e intrafoliais, além de kinks. Em superlície, estão muito alterados e friáveis e são revestidos por uma carapaça de material ferruginoso, goctítico, limonítico c brechóide (canga). Em subsuperfícic, podem ser mais coesos e duros. Os contatos entre as formações descritas apresentam-se cisalhados, cataclasados e perturbados pelos sucessivos eventos deformacionais que afetaram a área.

A evolução do Anticlinal de Mariana foi descrita por Nalini Jr. (1993) segundo dois eventos: um extensional $\mathrm{e}$ um compressional subseqüente. O primeiro desenvolveu dobras regionais, dobras parasíticas, foliação $\left(\mathrm{S}_{\mathrm{cx}}\right)$ paralela ao acamamento, fraturas de tração preenchidas por veios, ocorrência generalizada de tension gashes e falhas normais. Ao evento extensional é atribuída a omissão de unidades litoestratigráficas em algumas seções. Os mecanismos de geração das dobras principais são o deslizamento e/ou fluxo flexural, com geração localizada de uma foliação associada $\left(\mathrm{S}_{\text {, }}\right.$ ). Esse evento extensional foi responsável pela nucleação da Sinclinal Dom Bosco, do Anticlinal de Mariana, além de outras dobras parasíticas através do soerguimento do embasamento da região, e pelo arqueamento das seqüências supracrustais dos Supergrupos Rio das Velhas e Minas.

O evento compressional é caracterizado por transporte tectônico de leste para oeste e apresenta três fases deformacionais, segundo Nalini Jr. (1993). A fase $D_{1}$ gerou uma foliação metamórfica $S_{1}$ e milonítica $\mathrm{S}_{\mathrm{ml} \text {. }}$ paralelas, com máximo em $\left(\mathrm{N} 78^{0} \mathrm{E} / 18^{0} \mathrm{SE}\right)$. Sobre esses planos desenvolveu-se uma lineação de estiramento mineral com atitude S27\% $09^{()}$ealém de charneiras de dobras isoclinais e intrafoliais sub-paralelos à lineação de estiramento com rumo em S36 $6^{\circ} \mathrm{E} / 30^{\circ}$. Todas essas estruturas ocorrem associadas a fallhas reversas mergulhando para oeste. A Fase $\mathrm{D}_{2}$ gerou clivagem de crenulação $\left(\mathrm{N} 76^{\circ} \mathrm{E} / 87^{\circ} \mathrm{SE}\right)$ e lineação dc crenulação associada, com rumo $S 15^{\circ} \mathrm{E} / 12^{\circ}$, além de raras dobras abertas com cixo EW e falhas direcionais aproximadamente EW. À fase $D_{3}$ associam-se clivagem de crenulação $\left(\mathrm{N} 03^{\circ} \mathrm{E} / 60^{\circ} \mathrm{NW}\right)$ e lineação de crenulação $\left(\mathrm{S} 15^{(0} \mathrm{W} / 15^{0}\right)$, dobras abertas mesoscópicas com charneiras rumando para $\left(\mathrm{S} 24^{0} \mathrm{~W} / 15^{\circ}\right)$ a megascópicas NS, bem como de lraturamento generalizado $\left(\mathrm{N} 87^{\circ} \mathrm{E} / 90^{\circ}, \mathrm{N} 75^{\circ} \mathrm{E} / 87^{\circ} \mathrm{NW}\right)$.

O flanco sul do anticlinal, que atualmente constitui a serra de Ouro Preto, foi gerado na fase $\mathrm{D}_{1}$ que também corresponde a uma rampa lateral com movimento dextral. Esse flanco sul foi afetado por uma deformação de maior magnitude, apresentando grandes dobras, rampas oblíquas e laterais definindo um subdomínio estrutural regional (ver Nalini Jr. 1993).

VEIOS DE QUARTZO Os veios de quartzo, objetos do presente trabalho, foram, em parte, caracterizados e subdivididos primeiramente por Lacourt (1937). Dorr (1969) fez uma caracterização genética regional dos veios de quartzo que ocorrem no Quadrilátero Ferrífero. Posteriormente, Nalini Jr.(1993) estudou em maior detalhe os veios de quartzo da região e os subdividiu cm cinco lamílias, sendo que somente três delas são mineralizadas. Oliveira (1998) definiu cinco famílias de veios de quartzo no depósito aurífero de Passagem de Mariana e relacionou à evolução tectônica $\mathrm{c}$ à mineralização desse depósito.

Formas e dimensões dos veios As formas e dimensões dos veios, na natureza, são infinitas e fractais. No entanto, para melhor entendimento e tratamento desses veios, eles foram classificados de acordo com suas posições em relação às foliações principais, anteriormente descritas, das rochas encaixantes e, basicamente, podem ser considerados de três tipos: discordantes, parcialmente concordantes e concordantes. Os primeiros podem cortar a foliaçĩo principal da rocha de forma vertical ou inclinada. Os do segundo tipo normalmente acompanham a foliação da rocha encaixante, mas têm um mergulho mais elevado do que ela. Os do terceiro tipo são aqueles veios que acompanham totalmente a foliação das encaixantes. Para facilitar o estudo desses veios, eles foram codificados de acordo com essas características:

VEIOS DISCORDANTES (QDV) Encontram-se principalmentc encaixados nos quartzitos da Formação Moeda (Figura 2). Podem, no entanto, ser observados em outras unidades. O grálico da Figura 3 mostra as direções preferenciais destes veios, nas três áreas estudadas. Esse grálico compõe-se pelo estereograma dos pólos dos planos e pela roseta das suas direções. Foram medidos 159 veios e a direção média é de N54E. As medidas foram obtidas $\mathrm{em}$ superfície, nas áreas aflorantes do quartzito.

Suas dimensões variam desde milímetros metros, tanto na largura como $\mathrm{cm}$ comprimento. As seções transversais desses veios são de diversas formas: retas, anastomosadas, bifurcadas, transectantes e caóticas (Figura 2).

VEIOS PARCIALMENTE CONCORDANTES (QCI) Esses veios encontram-se preferencialmente encaixados nos quartzitos da Formação Moeda, de forma parcialmente concordante com a foliação, $\mathrm{e}$ inclinados com mergulho mais elevado que esta. São de dimensões centimétricas, predominantemente, e têm seções transversais elípticas alongadas. O estereograma das atitudes desses veios (Figura 3 ) apresenta uma concentração de valor máximo em N80" W, $30^{\circ} \mathrm{SW}$.

VEIOS CONCORDANTES (ICl, FCl) São os veios que concordam, totalmente, com a foliação metamórfica. São principalmente do tipo ICI, isto é, encontram-se encaixados nos itabiritos da Formação Cauê. São de dimensões predominantemente milimétricas em espessura, com os comprimentos podendo atingir dimensões métricas.

Características petrográficas Os veios do tipo QDV são, relativamente, os menos deformados e são caracterizados por uma trama cristalina, onde os cristais constituintes são de maiores dimensões (200 micra a $20 \mathrm{~mm}$ ). Os contatos entre os grãos são, predominantemente, 

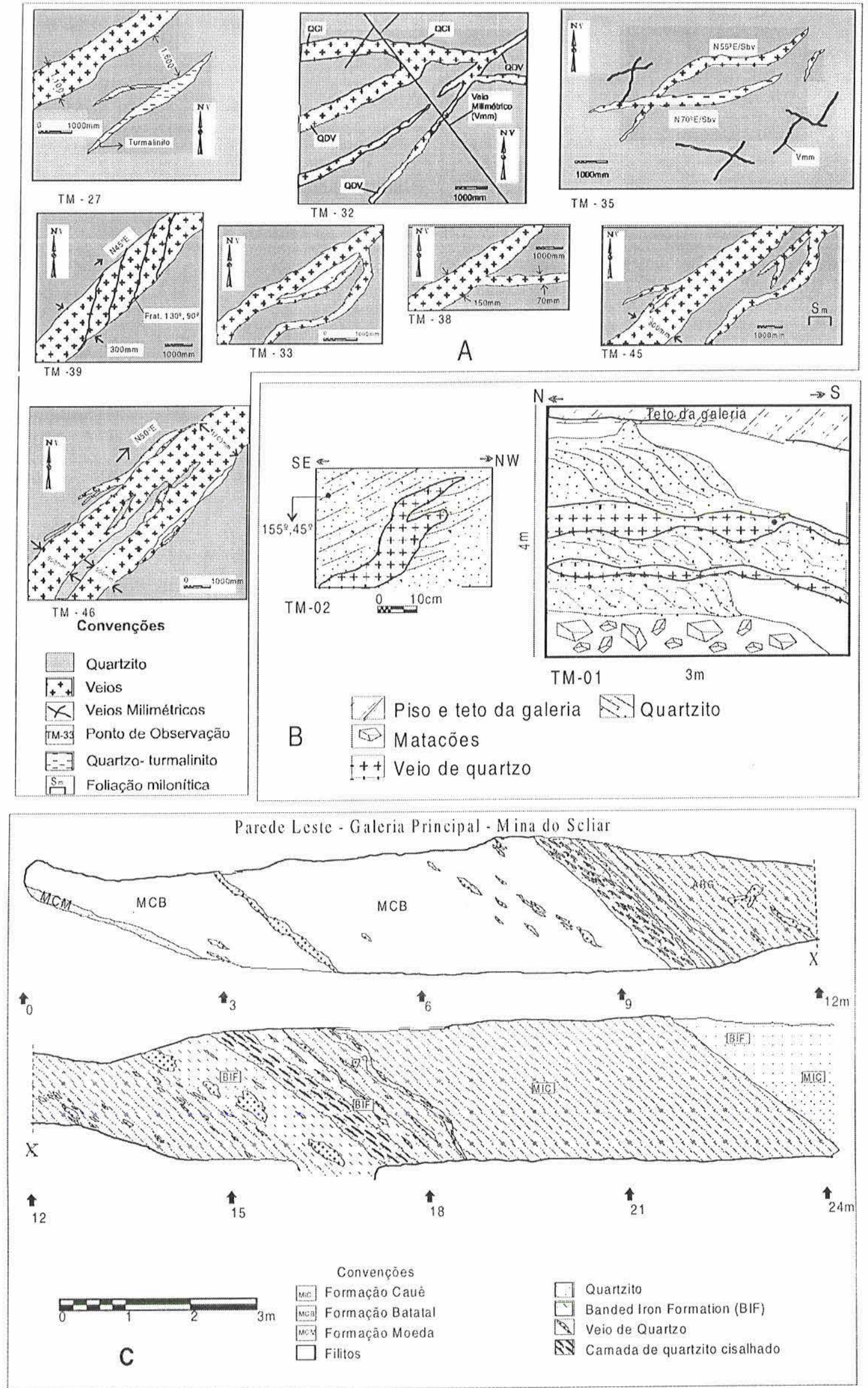

Figura 2 - Representação esquemática das diversas formas em que os veios apresentam. Quadro A (vista em planta): veios discordantes (QDV); Ponto TM27 veio tabular e bifucado: Ponto TM-32 veios cá́ticos: Ponto TM-35 veios transectantes: Ponto TM-39 veio tabular com fraturas sigmoidais; Ponto TM33 veios anastomosados: Ponto TM-38 veio bifurcado: Ponto TM-45 veios bifurcados e anastomosados: Ponto TM-46 idem. Quadro B (vista em perfil): veios parcialmente concordantes (QCI) e Quadro C (vista em perfil): veios concordamtes (FCl e ICl). 


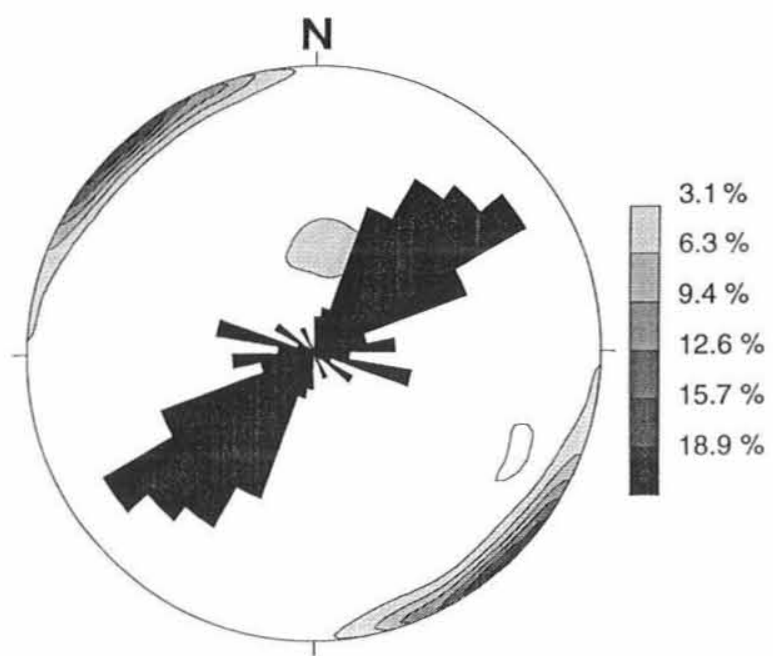

Figura 3 - Diagrama de isolinhas dos pólos dos planos e de rosetas dos reios que ocorrem encaixados nos quartzitos (QDV's+QClis) da Formașo Moeda. Numero de medidas $=159$

retos ou suavemente curvos, localmente denteados. Podem ocorrer subgrãos (incipientes) e é comum a textura indicativa para crescimento estático de grãos, reforçada pela presença de pequenos grãos de $\mathrm{mm}$ segundo mineral, geralmente turmalina, com uma orientação preferencial, os quais estão incluídos nos grãos do mineral principal (Passchier e Trouw 1996, p.47). Essas características são evidências da ocorrência de recristalização estática cujo principal mecanismo é "grain boundary area reduction" (GBAR). Tal recristalização pode ocorrer durante a deformação, mas seu efeito é mais óbvio e abundante depois de cessada a deformação, especialmente a altas temperaturas (Passchicr c Trouw 1996, p. 43). Podem ocorrer "novos grãos" nos contatos entre os grãos maiores e evidências de migração das fronteiras de grãos ("grain boundary migration" = GBM). As fraturas são predominantemente intragranulares. No entanto, podem ocorrer fraturas transgranulares poligonais em pares conjugados.

Os veios QCI são mais deformados que os veios QDV, por possuírem uma trama parcial a totalmente cataclasada, caracterizada por estruturas fragmentárias e texturas granuloblásticas, onde os contatos entre os grãos ( 100 micra a $2 \mathrm{~mm}$ ) são predominantemente suturados e denteados. Há uma predominância dos "novos grãos", que apresentam extinções planares e ondulantes. A predominância de frontciras de grãos altamente irregulares, caracterizando o processo de recristalização por "grain boundary migration" (GBM), evidencia a recristalização dinâmica na formação desses veios. As fraturas ocorrem generalizadamente entre c intragrãos, com predominância das últimas.

Os veios ICI são, relativamente, os mais intensamente deformados. São caracterizados por uma trama completamente recristalizada com orientação incipiente dos grãos. Os novos grãos (100 micras) podem apresentar contornos aparentemente hexagonais e contatos retos, caracterizando uma textura granuloblástica poligonal incipiente. As fraturas são essencialmente transgranulares. Os opacos, que ocorrem com uma porcentagem de cerca de $50 \%$, podem incluir minerais sulfetados com ouro.

\section{ANÁLISE DOS DADOS E RESULTADOS Tratamento dos}

dados De posse dos dados de espessura, comprimento, largura, afastamento e direção dos veios, procedeu-se ao tratamento estatístico desses valores com auxílio do programa Excel, da Microsoft.

Em primeiro lugar, abriu-se uma pasta para "tabelas de dados", onde os valores correspondentes às diversas medidas são plotados. Os números correspondentes aos dados de números de veios são colocados $\mathrm{em}$ ordem crescente, enquanto os valores de espessuras, comprimentos e afastamentos são ordenados em ordem decrescente, em colunas separadas.

A seguir, procedeu-se à análise dos dados através de gráficos de dispersão, escala $\log -\log$, com ajuste de linha de tendência potencial. Nesses gráficos, são obtidas as equações potenciais correspondentes à linha de tendência e também é obtido o grau de ajuste aos dados, através do coeficiente de correlação $\left(R^{2}\right)$.

Foram confeccionados três gráficos para cada litologia (log comprimento vs. log espessura, log número de veios vs. log espessura e log número de veios vs. log afastamento). Devido à exiguidade de espaço apenas alguns grálicos são exibidos, a título de exemplo. Os resultados dos grálicos obtidos estão mostrados na Tabela 1 para facilitar o manuseio dos mesmos. A Figura 4 apresenta um exemplo desses gráficos.

Análise geométrica dos veios $\mathrm{O}$ tratamento estatístico dos dados coletados para os veios de quartzo permitiu que se determinasse a dimensão fractal desses veios, nas seções trabalhadas.

A análise gcométrica dessas dimensões é feita por "famílias" de gráficos. Dessa maneira, serão analisados os valores das dimensões fractais obtidos nos diversos tipos de gráficos, procurando-se interpretar o seu significado geométrico, em cada seção.

A Gcometria Fractal, de certa forma, é um artifício de transformação de dados geológicos em números que têm um signilicado geométrico. A Gcometria Euclidiana clássica faz corresponder ao ponto a dimensão zero, à linha, a dimensão um, ao plano, a dimensão dois e 'a esfera (volume ideal), a dimensão três. As dimensões fractais lracionárias representam feições geométricas intermediárias, entre as formas geométricas clássicas da Geometria Euclidiana. Assim dimensões com valores entre zero e um representam feições com características geométricas pontuais a lineares.

\section{GRÁFICOS LOG NÚMERO DE VEIOS VERSUS LOG ESPESSURA}

A espessura é a medida direta mais confiável c correta entre todas as demais, isto porque a medida do comprimento de um veio nem sempre pode ser obtida diretamente $\mathrm{e}$ a medida do afastamento também não é exata, porque deve ser tomada perpendicularmente às direções dos veios, o que nem sempre é possível de se realizar. Por isso considerase a dimensão fractal mais significativa a que foi obtida a partir dos gráficos $\log \mathrm{N} X \log \mathrm{E}$.

O significado geométrico desses gráficos pode ser obtido a partir da análise da equação potencial obtida pelo ajuste linear dos valores de $\mathrm{Y}$ $\mathrm{cm}$ função dos valores de $\mathrm{X}$ (espessura). Os valores da dimensão fractal D que se aproximam de um correspondem a expressões geométricas próximas à da linha, ao passo que valores de $\mathrm{D}$ que se aproximam de zero correspondem a expressões geométricas próximas às do ponto. Em outras palavras, quando a dimensão D aproxima-se da unidade, isto significa que a forma do veio tende a um formato linear (o veio teria sido estirado) e quando o valor da dimensão $\mathrm{D}$ vai diminuindo $\mathrm{e}$ tendendo a zero significa que o veio foi espessado, na medida em que uma dimensão não excede em muito a outra.

Os veios encaixados nos itabiritos (ICI) apresentaram as seguintes dimensões: 0,9183 (Veloso); 0,8371 (Lajes) e 0,824 (Pieta). Os veios encaixados nos quartzitos (QDV c QCI) mostraram os valores seguintes: 0,868 (Veloso); 0,6667 (Lajes) c 0,6283 (Pieta). Os veios encaixados nos filitos passaram de 0,8586 (Lajes) para 0,4864 (Pieta). Todas as dimensões fractais desses veios sofreram uma diminuição de valores de oeste para leste, do Bairro do Veloso para o Bairro do Taquaral. Os veios encaixados nos quartzitos discordantemente (QDV's) também mostram essa diminuição nos seus valores das dimensões fractais: 0,7959 (Veloso); 0,6654 (Lajes) e 0,5334 (Pieta).

Do ponto de vista geométrico, o decréscimo dos valores de D indica que os veios tornam-se mais espessos de oeste para leste, ao longo da serra de Ouro Preto, o que foi, posteriormente, corroborado por observações de campo. Os veios encaixados nos itabiritos (ICI's) e filitos (FCI's), lenticulares, passam da forma de seções alongadas, próximas a lineares, para seções lenticulares mais amendoadas ou nodulares. Os veios encaixados nos quartzitos, principalmente os QDV's, tornam-se mais espessos, no mesmo sentido, de oeste para leste (Figura 5). 
Tabela I - Resultado dos gráficos log-log.

\begin{tabular}{|c|c|c|c|c|c|c|c|}
\hline Gráfico & Litologia & $\mathrm{Y} \times \mathrm{X}$ & N. Dados & Eq. Potencial & $\mathrm{R}^{2}$ & D (Dim. Fractal) & LOCAL \\
\hline $4 \mathrm{~A}$ & itabirito & log comp. $x \log$ esp. & 140 & $Y=16,34 x^{1,2957}$ & 0,9161 & 1,2957 & Veloso \\
\hline $4 \mathrm{~B}$ & itabirito & $\log n . v \operatorname{cios} \mathrm{x} \log$ esp. & 140 & $\mathrm{Y}=235,78 \mathrm{x}^{-0.9183}$ & 0,9719 & 0,9183 & Veloso \\
\hline $4 \mathrm{C}$ & itabirito & $\log$ n.veios $x \log$ afast. & 140 & $Y=1234 x^{-0,7138}$ & 0,7182 & 0,7138 & Veloso \\
\hline 4D & quartzito & $\log$ comp. $x \log$ esp. & 58 & $Y=22,082 x^{1,0897}$ & 0,9715 & 1,0897 & Veloso \\
\hline $4 \mathrm{E}$ & quartzito & $\log$ n.veios $x \log$ esp. & 58 & $Y=515,25 x^{-0,868}$ & 0,879 & 0,868 & Veloso \\
\hline \multirow[t]{19}{*}{$4 \mathrm{~F}$} & quartzito & $\log$ n.veios $x \log$ afast. & 58 & $\mathrm{Y}=368,23 \mathrm{x}^{-0,42}$ & 0,9459 & 0,42 & Veloso \\
\hline & itabirito & $\log$ comp. $x \log$ esp. & 154 & $Y=15,15 x^{1.0655}$ & 0,9805 & 1,0635 & Lajes \\
\hline & itabirito & $\log$ n.veios $x \log$ esp. & 154 & $Y=361,33 x^{-0 ., 8371}$ & 0,9063 & 0,8371 & Lajes \\
\hline & itabirito & $\log$ n.veios $\mathrm{x} \log$ afast. & 154 & $\mathrm{Y}=2476,1 \mathrm{x}^{-0.7612}$ & 0.885 & 0,7612 & Lajes \\
\hline & filito & $\log$ comp. $x \log$ esp. & 42 & $Y=3,6194 x^{1.2006}$ & 0,9165 & 1,2006 & Lajes \\
\hline & filito & $\log n . v \operatorname{cios} x \log$ esp. & 42 & $\mathrm{Y}=328,8 \mathrm{x}^{-0.8586}$ & 0,7722 & 0,8586 & Lajes \\
\hline & filito & $\log$ n.veios $x \log$ afast. & 42 & $Y=96,1 x^{-(0,3807}$ & 0,7115 & 0,3807 & Lajes \\
\hline & quartzito & log comp. $x \log$ esp. & 52 & $\mathrm{Y}=51,492 \mathrm{x}^{(0,7996}$ & 0,9481 & 0,7996 & Lajes \\
\hline & quartzito & $\log$ n.veios $x \log$ esp. & 52 & $Y=839,46 x^{0,6667}$ & 0,7918 & 0,6667 & Lajes \\
\hline & quartzito & $\log$ n.veios $x \log$ afast. & 52 & $\mathrm{Y}=4355,1 \mathrm{x}^{0,6056}$ & 0,6696 & 0,6056 & Lajes \\
\hline & itabirito & $\log$ comp. $x \log$ esp. & 98 & $\mathrm{Y}=24,98 \mathrm{x}^{1,0947}$ & 0,92 & 1,0947 & Picta \\
\hline & itabirito & $\log$ n.veios $x \log$ esp. & 98 & $\mathrm{Y}=155.85 \mathrm{x}^{-0.824}$ & 0,9254 & 0,824 & Pieta \\
\hline & itabirito & $\log$ n.veios x log afast. & 98 & $\mathrm{Y}=1450,6 \mathrm{x}^{-0.9226}$ & 0,8456 & 0,9226 & Pieta \\
\hline & filito & $\log$ comp. $x \log \mathrm{csp}$. & 18 & $Y=17,186 x^{0.8186}$ & 0,9066 & 0,8186 & Pieta \\
\hline & filito & $\log n . v \operatorname{cios} x \log$ esp. & 18 & 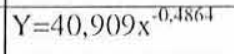 & 0,8589 & 0,4864 & Picta \\
\hline & filito & $\log$ n.veios $x \log$ afast. & 18 & $Y=182,24 x^{-0.5387}$ & 0,6989 & 0,5387 & Picta \\
\hline & quartzito & log comp. $\mathrm{x}$ log esp. & 51 & $Y=18,611 x^{0.9656}$ & 0,9464 & 0,9656 & Picta \\
\hline & quartzito & $\log n . v e i o s x \log$ esp. & 51 & $\mathrm{Y}=615,52 \mathrm{x}^{-0,62 \mathrm{x} 3}$ & 0,7262 & 0,6283 & Pieta \\
\hline & quartzito & $\log$ n.veios $x \log$ afast. & 51 & $\mathrm{Y}=7811 \mathrm{x}^{-0.6528}$ & 0.8471 & 0,6528 & Picta \\
\hline
\end{tabular}

GRÁFICOS LOG COMPRIMENTO VERSUS LOG ESPESSURA Os gráficos log comprimento vs. log espessura foram utilizados por Johnston e McCaffrey (1996) para demonstrar que o comprimento (C) dos veios é proporcional à sua espessura (e) e que a constante de proporcionalidade $\mathrm{K}\left(\mathrm{C}=\mathrm{K} \cdot \mathrm{e}^{\mathrm{D}}\right)$ é função do campo de tensões e do comportamento reológico das encaixantes. Trata-se, portanto, de uma excelente medida do fator de forma desses veios. Esta relação, entretanto, tem caráter puramente empírico, tendo sido determinada a partir da análise de uma população de 1320 indivíduos. Esses autores demonstraram que o cisalhamento simples em rochas macias (filito, itabirito) produz veios com relação axial baixa e com pequenos valores de $\mathrm{K}$, enquanto a extensão pura em rochas duras resultam numa relação axial alta e grandes valores de K. Segundo esses autores, os valores das dimensões fractais nesses grálicos correspondem aos valores de veios pequenos, quando $\mathrm{D}$ é sempre maior do que um $(1,0) \mathrm{e}$ para veios grandes D é sempre menor que 1.

O significado geométrico da dimensão D, obtida através desses gráficos (Figura 4 e tabela 1), podem ser assim relacionado: quanto maior for essa dimensão menor é a dimensão (tamanho) dos veios de quartzo e quanto menor for essa dimensão fractal, maior será a dimensão do veio. Outro significado desses gráficos indica, obviamente, que o comprimento dos veios é diretamente proporcional à sua espessura. Em outras palavras, quanto mais espesso é o veio maior será seu comprimento.

Observa-se que a dimensão fractal dos veios diminui de oeste para leste para os veios encaixados nos itabiritos e filitos. Para os quartzitos e itabiritos, essas dimensões diminuem da área do Veloso para a área das Lajes e tornam a aumentar das Lajes para a área da Piedade. Os valores, para os itabiritos, são: 1,2957 (Veloso); 1,0635 (Lajes) c 1,0947 (Pieta). Para os quartzitos, os valores são: 1,0897 (Veloso); 0,7996 (Lajes) e 0,9656 (Pieta). Os valores, para os veios encaixados nos filitos, sāo: 1,2006 (Lajes) e 0,8186 (Pieta). As dimensōes para os dados totais são: itabirito $\mathrm{D}=1,1322$ (menores veios); quartzitos $\mathrm{D}=$ 0,8519 (veios maiores) e filito $\mathrm{D}=1,02$ (veios intermediários a pequenos).

Esse decréscimo está de acordo com o proposto por Johnston e McCaffrey (1996), pois D>1,0 para os veios encaixados nos itabiritos c filitos e $\mathrm{D}<1,0$ para os veios encaixados nos quartzitos.

A interpretação desses dados, portanto, indica que os veios encaixados nos filitos tendem a aumentar de tamanho no sentido de oeste para leste. Os veios encaixados nos itabiritos e quartzitos mostram, no geral, a mesma tendência. No entanto, a dimensão fractal menor situase na área das Lajes, indicando que os veios de maiores dimensões encontram-se nesse local, seguindo-se os veios do Taquaral e, por último, os veios do Veloso, que são, portanto, os de menores dimensões entre os veios encaixados nos itabiritos c quartzitos.

$\mathrm{O}$ valor da constante $\mathrm{K}\left(\mathrm{C}=\mathrm{K} . \mathrm{L}^{\mathrm{D}}\right)$, para os sistemas analisados, varia de 3,6 a 24,9 , para os itabiritos e filitos, e de 18,6 a 51,4 , para os quartzitos. Para os veios dos itabiritos e filitos, o valor diminui do Veloso para Lajes e aumenta desta área para a da Piedade. Para os veios dos quartzitos, $\mathrm{K}$ aumenta do Veloso para Lajes e diminui desta última para a área da Piedade. Essa mudança pode representar variaçōes na reologia dos materiais encaixantes, que não pode ainda ser avaliada, com base nos dados disponíveis.

GRÁFICOS LOG NÚMERO DE VEIOS VERSUS LOG AFASTAMENTO Esses gráficos foram obtidos através da ordenação dos valores de afastamento em ordem decrescente. Eles relacionam o número acumulado (total) de veios com a medida de seus afastamentos, isto é, com a medida de suas separações tomadas em direções perpendiculares à direção desses veios (Figura 4, e Tabela 1).

O significado geométrico dos valores das dimensões fractais, obtidos a partir desses gráficos, indica que esses valores correspondem à 

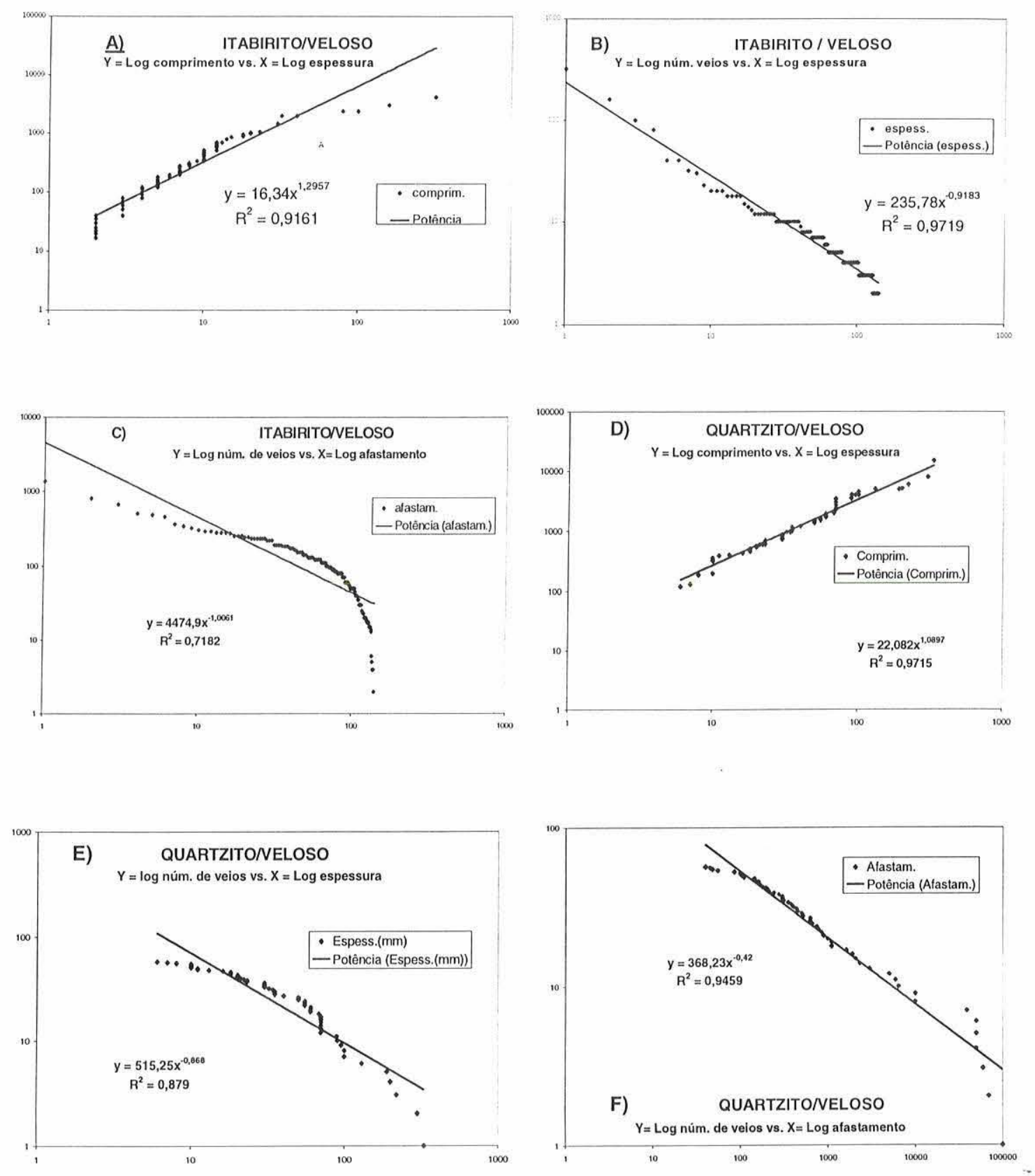

Figura 4 - Exemplo de gráficos log-log, área Veloso. A. Itabirito, log comprimento X log espessura. B. Itabirito, log núm. de veios X log espessura. C. Itabirito log num. de veios X log afastamento. D. Quartzito, log comprimento x log espessura. E. Quartzito, log núm. de veios X log espessura. F. Quartzito, log núm. de veios $X \log$ afastamento.

densidade ou quantidade de veios por metro linear; $\mathrm{cm}$ outras palavras, D maior significa maior concentração de veios. Para se verificar a assertiva é necessário comparar os valores entre as diversas litologias. Os veios encaixados nos itabiritos são os que mais se concentram, e portanto são os que têm maior dimensão fractal. Graficamente, isso corresponde à maior inclinação da reta e a uma faixa mais estreita e de menor valor para os afastamentos.

Os valores das dimensões fractais para os veios ICI são: 0,7138 (Veloso); 0,7612 (Lajes) e 0,9226 (Pieta). Os veios QDV apresentaram os seguintes valores para essas dimensões fractais: 0,42 (Veloso); 0,6056 (Lajes) e 0,6528 (Pieta). As dimensões para os filitos variaram de 0,3807 (Lajes) para 0,5387 (Pieta). Todas as dimensões são crescentes no sentido de oeste para leste (Figura 5).

Verifica-se, com base nos dados de campo, que o valor da dimensão fractal é diretamente proporcional ao adensamento dos veios, isto é, quanto maior a dimensão fractal dos veios para seus afastamentos mais próximos estão, uns dos outros, esses veios. Portanto, para todas as litologias, o adensamento relativo da quantidade de veios é maior para leste da serra de Ouro Preto, com tendência à diminuição para oeste (Figura 5).

IMPLICAÇÕES GEOLÓGICAS A análise empreendida, caracterizando-se diversos valores da Dimensão Fractal D para parâmetros geométricos dos sistemas de veios que ocorrem na serra de Ouro Preto, representa, na verdade, uma aferição do fator de forma dos veios, numa análise comparativa. Essa abordagem constitui-se em mais um elemento da análise descritiva, visando-se à avaliação dos processos de colocação desses veios.

Deve-se novamente enfatizar que os sistemas de veios são atribuídos a gerações distintas, fato que pode ser confirmado pela análise das relações de corte e superposição, pelos estudos petrográficos e pela trama dos mesmos. Tais gerações, portanto, refletem processos de formação distintos e, certamente, diacrônicos.

As dimensões obtidas para as espessuras dos veios encaixados nos 

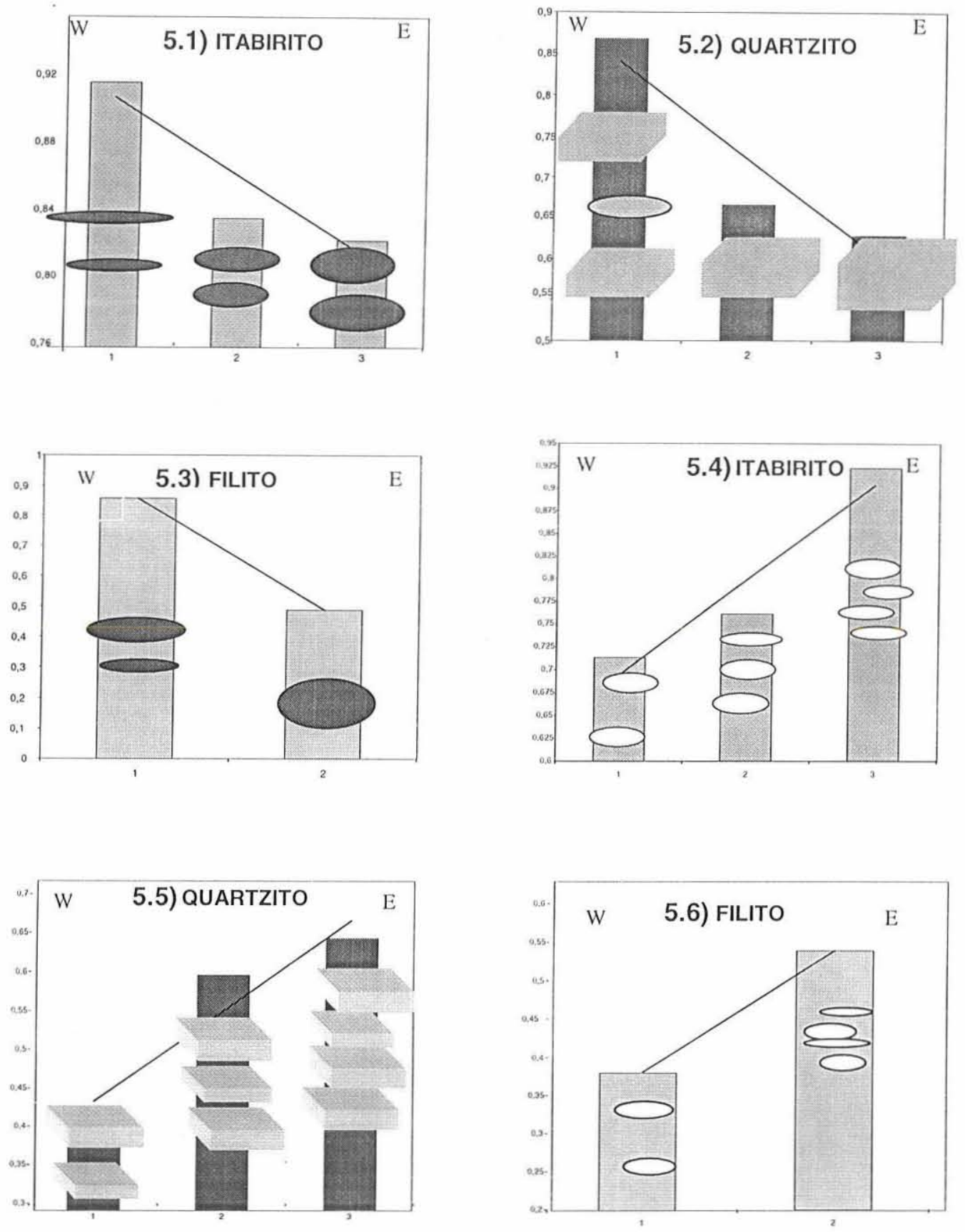

Figura 5 - Variações das dimensões fractais, de oeste para leste, obtidas para os sistemas de veios, encaixados nas diversas litologias, com base nos gräficos log-log, associadas às formas idealizadas para esses sistemas. 5.1: itabirito, gráfico log múmero de veios Xlog espessura. 5.2: quartzito, gráfico log número de veios X log espessura. 5.3: filito, gráfico log mímero de veios X log espessura. 5.4: itabirito, gráfico log número de veios X log afastamento. 5.5: quartzito: gráfico log número de veios $X \log$ afastamento. 5.6: filito: gráfico log número de veios $X \log$ afastamento. Local: $I=$ Veloso, $2=$ Lages, $3=$ Piedade/Taquaral

itabiritos (ICI) e filitos (FCI), por exemplo, mostram, claramente, que os veios passam de um comportamento geométrico planar (oblato), a oeste da serra de Ouro Preto, para um comportamento "nodular" (prolato), para leste. Em outras palavras, o itabirito tende a ser "normal", para oeste; enquanto, para leste, o mesmo apresenta-se mais remobilizado, com tendência maior de concentração em "bolsōes". Para os veios encaixados nos quartzitos (QDV+QCI) observa-se que a tendência de remobilização é a mesma de oeste para leste. No campo fica evidente que existem mais veios parcialmente concordantes (QCI) a oeste (Veloso) do que para leste (Taquaral).

As dimensões fractais obtidas para os afastamentos dos veios mostraram que, para todos os litotipos estudados, o adensamento ou frequiência de veios, por metro linear, aumenta de oeste para leste ou seja, à medida que se caminha para leste, na serra de Ouro Preto, o número de veios por metro linear é maior, ou ainda, a quantidade de quartzo mobilizado c concentrado sob a forma de veios aumenta de oeste para leste.

Com relação às dimensões dos veios, cujos parâmetros analíticos são os valores das dimensões fractais obtidas dos gráficos log de comprimento $\mathrm{X} \log$ espessura, observa-se como tendência geral, o aumento de tais dimensões, também de oeste para leste, ou seja, os veios aumentam em comprimento e espessura para leste da serra de Ouro Preto. Apesar dessa tendência geral, os maiores veios encontrados, tanto para os encaixados nos itabiritos como para os encaixados nos quartzitos, encontram-se na área do Bairro das Lajes. Isto justifica portanto ser esta a região mais intensamente trabalhada na extração de ouro.Observa-se que a dimensão fractal é sempre maior para os veios concordantes (FCI e ICI) sendo menor para os veios parcialmente concordantes (QCI) e menor ainda para os veios discordantes. Como foi apontado anteriormente, os veios concordantes são os mais afetados 
tectônicamente por serem os mais antigos, seguidos pelos parcialmente concordantes e depois pelos discordantes, que scriam, portanto, os veios mais novos.

Com base na literatura, um modelo conceitual cvolutivo para a serra de Ouro Preto (Endo \& Fonseca 1992, Nalini Jr. 1993, Endo 1997 c Cavalcanti 1999) envolveria dois eventos principais: um evento de natureza extensional, atuando nas supracrustais, tendo sido nucleado pela ascensão de corpos do embasamento, numa típica tectônica tipo dome and keel. Essa tectônica é responsável, em grande parte, pelas freqüentes omissões de camadas, pela quase impossibilidade de balanceamento das seções, pela formação de "altos estruturais", que viriam a se instalar na forma de obstáculos ao evento contracional que se segue, c, ainda, pela criação de espaço para colocação dos sistemas de veios mais antigos, tais como os ICI, FCI c QCI. A direção do vetor dessa extensão, segundo diversos autores, ć de NW para SE.

$\mathrm{O}$ evento contracional posterior tem como condições de contorno a configuração decorrente da extensão. Os altos do embasamento funcionam como obstáculos à propagação de matéria para o antepaís, havendo, assim, a nucleação de falhas curvas. Dessa forma, por exemplo, o Sistema Fundão-Cambotas (Endo c Fonseca 1992) mostra forte influência do Domo de Bação e sua extensão para sul é praticamente controlada pelo Domo de Santa Rita (Figura 6).

O evento contracional organiza-se, assim, de forma complexa no espaço e também no tempo. Os autores são unânimes em considerar a geração de duas ou três famílias de estruturas, que se enquadram no contexto evolutivo desse evento. Tanto para a região do Anticlinal de Mariana (Nalini Jr. 1993, Oliveira 1998), como para a borda leste (Ferreira Filho 1999), várias gerações de estruturas são descritas, enquadrando-se, aí, os próprios sistemas de veios abordados no presente trabalho.

A estruturação contracional tem início com a nucleação de falhas. Estas, à leste de Mariana, envolvem o embasamento e têm sua geometria fortemente controlada pelos altos estruturais. Rampas oblíquas são também nucleadas, sendo o caso específico da área em estudo, onde se configura um sistema reverso oblíquo dextral (Endo e Fonseca 1992).

Enquadrando-se os sistemas de veios $\mathrm{ICI}, \mathrm{FCI}$ e QCI cm tal contexto duas hipóteses podem ser formuladas: as fontes das fases fluidas que preencheram fraturas de tração estavam situadas mais para leste, ou há um aumento da magnitude de deformação em direção a leste.

A hipótese $1 \mathrm{tem}$ sentido geológico, pois, de fato, os veios-camadas concordantes e envolvidos pela tectônica contracional encontram-se em quantidades mais profusas $\mathrm{cm}$ direção a leste, onde o depósito de Passagem vem a englobar os corpos de maior dimensão. Por outro lado, os níveis mineralizados concordantes tendem ao desaparecimento em direção a oeste, a partir da cidade de Ouro Preto. Assim, a última ocorrência aurífera, com algum significado, reportada no flanco sul, $\mathrm{em}$ análise nesse artigo, situa-se nas imediações da Fazenda Caieira, a aproximadamente $8 \mathrm{~km}$ a oeste da zona do Bairro Veloso. Nesse intervalo, praticamente inexistem veios concordantes na formação ferrílera.

O aumento da magnitude da deformação (hipótese 2) é fator decisivo na determinação da densidade de veios por metro linear. Isso porque os veios ICI, FCI e QCI são veios que se posicionam no plano da xistosidade e há evidências de boudinagem desses veios, com linha de "boudin" perpendicular ao eixo a cinemático. Esse processo é bastante comum, com os veios boudinados assimetricamente se prestando a ótimos indicadores cinemáticos, denotando o claro regime de movimento reverso dextral. Essa boudinagem, em última análise, gera novos veios, daí o aumento da concentração, por metro linear, em direção a leste. A comprovação da hipótese 2 pode ser feita a partir de um dado meramente intuitivo, pois, admitindo-se o antepaís a leste, a tendência normal é de decréscimo da deformação em direção ao oeste. Quantitativamente, essa hipótese ainda não pode ser comprovada ou descartada, ao longo do flanco sul do Anticlinal de Mariana, pois inexistem trabalhos nesse sentido, principalmente por falta de bons marcadores da deformação. Porém, ao tomar-se o "espelho da estrutura", ou seja, seu flanco norte, a hipótese pode ser claramente comprovada.

Esta comprovação decorre de análises quantitativas da deformação efetuadas por Corrêa Neto e Dayan (1998) na área ao norte da serra de
Ouro Preto que cvidenciam, também, um aumento na deformação nos domínios estruturais situados a leste, quer dizer, a deformação aumenta de oeste para leste. Os autores mostram que a intensidade da deformação é a principal diferença entre os domínios estruturais analisados. $\mathrm{O}$ domínio oeste, de rampa frontal, apresenta estruturas primárias mais preservadas, enquanto o domínio leste, de rampa oblíqua, apresenta um paralelismo mais acentuado para os eixos- $X$ do elipsóide de deformação. Esse fato corrobora os dados encontrados pelas dimensões fractais, na serra de Ouro Preto, mostrando, ainda, que, em certo sentido, a Geometria Fractal pode ser utilizada para, qualitativamente, estimar a intensidade da deformação, sob condições geológicas favoráveis.

Os veios tardios, representados pelos QDV, em geral, mostram a mesma tendência que os veios mais antigos. Assim, de oeste para leste, os veios tendem para corpos mais nodulares, de maiores dimensões e com maior concentração por metro linear. Esses veios mostram características importantes: truncam a trama contracional, porém estão ainda deformados. Decorre daí a sugestão de que tenham surgidos nas fases finais do evento contracional. A única hipótese possível de formulação, a partir dos dados da análise geométrica fractal, é que a fonte das soluções estava, da mesma forma, situada mais para leste, próxima à zona periclinal do Anticlinal de Mariana. Essa hipótese pode ser comprovada, pois esses corpos estão presentes de forma profusa na Mina de Passagem, com a mesma característica ao longo do flanco sul: seu baixo ou inexistente teor em ouro.

Com relação ao mecanismo que gerou as fraturas preenchidas formando os veios QDV's, algumas hipóteses podem ser formuladas. Na posição de rampa lateral dextral, a primeira hipótese a ser considerada seria a de esses veios representarem "gashes" extensionais. Nesse caso, rumariam aproximadamente para noroeste, portanto, em posição exatamente oposta à posição real que ocupam, inviabilizando-se, assim, a hipótese. Para a região de Ouro Preto, outra alternativa seria a compatibilização da colocação dos veios com os dados estruturais coletados por Nalini Jr. (1993). Esse autor reporta uma terceira fase, de caráter contracional, com polaridade para oeste. Essa fase envolve dobramentos com vergência para oeste e charneiras caindo para sul. $\mathrm{O}$ caráter dos dobramentos é nitidamente flexural estando as camadas originais mergulhando para sul. Os veios QDV poderiam, portanto, representar veios de extensão associados ao dobramento flexural. O fato de estarem preferencialmente encaixados em quartzitos reforça a hipótese, pois, em termos reológicos, entre os litotipos analisados, o quartzito são rochas cujo comportamento reológico tende a uma resposta mais rúptil durante a evolução do processo de dobramento por deslizamento flexural. O modelo esquematizando a evolução dos sistemas de veios de quartzo está representado na Figura 6.

CONCLUSÕES Os sistemas de veios mais antigos (ICI, QCI, $\mathrm{FCl}$ ) foram gerados $\mathrm{cm}$ evento extensional. São cataclasados, sacaroidais e concordantes ou parcialmente concordantes com a foliação principal e foram deformados pelo evento contracional posterior: Os sistemas mais novos compreendem veios cristalinos e discordantes (QDV) e que foram gerados na fase final desse evento compressivo $\left(\mathrm{D}_{3}\right)$.

Os maiores veios encontram-se encaixados nos quartzitos da Formação Moeda, esses veios são normalmente tabulares e discordantes (QDV). Os veios menores que se encontram nos filitos (Formação Batatal) e nos itabiritos (Formação Cauê), são os que se apresentam normalmente lenticulares e concordantes com a foliação (FCI e ICI).

Com relação aos veios $\mathrm{ICI}, \mathrm{FCI}$ e QCI, conclui-se que suas formas, caracterizadas pela diminuição das dimensões fractais para leste, mudam de uma tendência planar, a oeste da serra, para um comportamento "nodular", para leste, sugerindo proximidade das fontes de fluidos e maior magnitude de deformação no sentido leste, durante o evento contracional. Relativamente aos veios QDV as dimensões fractais obtidas sugerem aumento de comprimento e espessura também no sentido oeste-leste, evidenciando proximidade da fonte dos fluidos para leste.

Os veios mais antigos têm uma dimensão fractal maior que os mais novos.

$\mathrm{O}$ valor da constante $\mathrm{K}\left(\mathrm{C}=\mathrm{K} . \mathrm{L}^{\mathrm{D}}\right)$, para os sistemas analisados, 


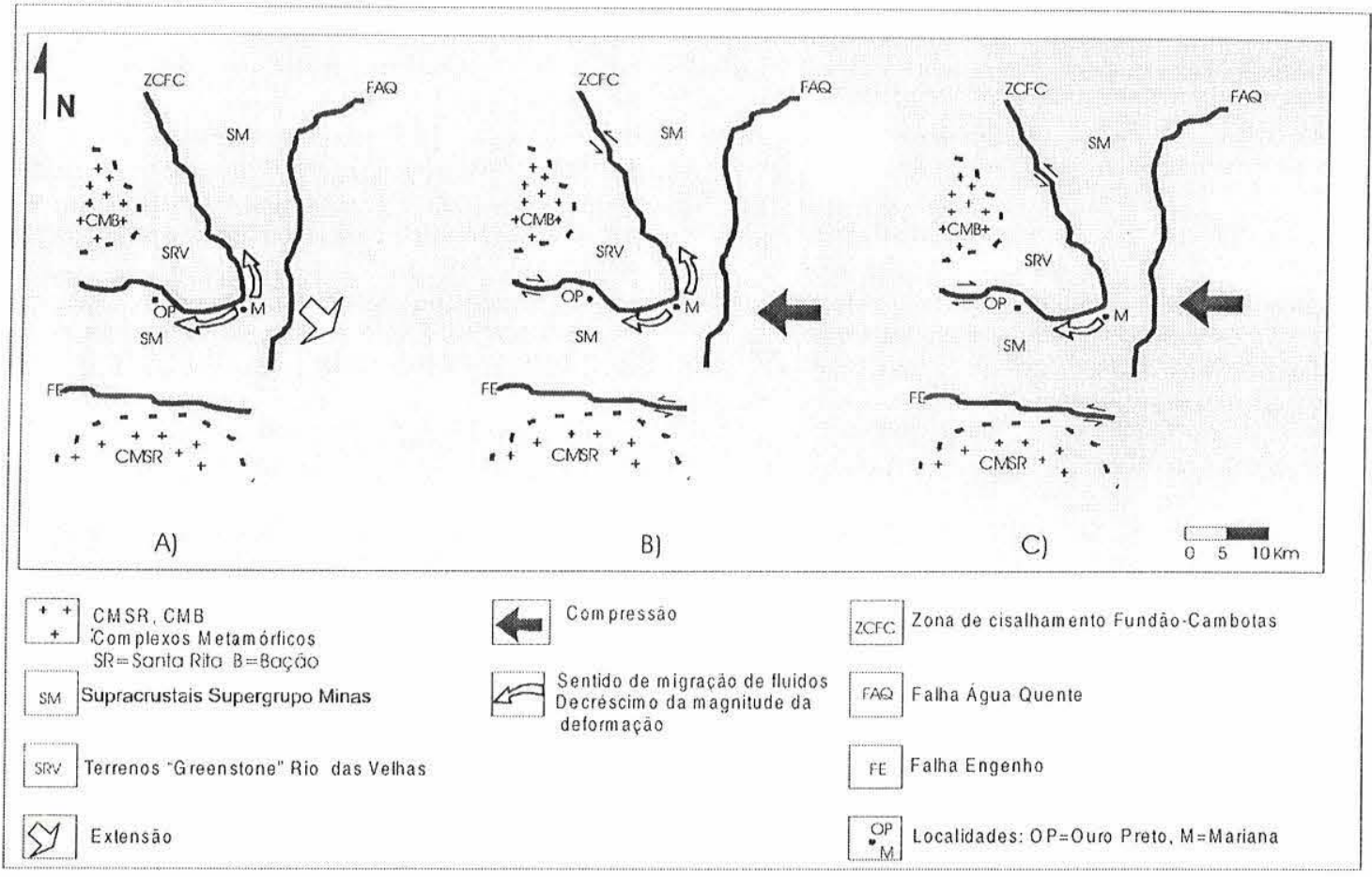

Figura 6 - Modelo da implantą:äo dos sistemas de veios, com base no estudo do contexto tectônico, realizado pelos diversos autores que trabalharam na região e nos resultados desse traballho, para a região da serra de Ouro Preto e anticlinal de Mariana.

varia de 3,6 a 24,9, para os itabiritos e filitos, e de 18,6 a 51,4 , para os quartzitos. Esse fato corrobora a formulação empírica de Johnston c McCaffrey (1996), para os quais veios pequenos produzem $D>1,0 \mathrm{c}$ veios maiores produzem $\mathrm{D}<1,0$.

A concentração dos veios é maior nos litotipos onde se encontram os veios de maior dimensão fractal, isto é, os valores das dimensões fractais, para os alastamentos dos veios, são diretamente proporcionais aos seus adensamentos. No caso analisado, o adensamento dos veios aumenta para leste da serra de Ouro Preto, indicando também uma maior magnitude de deformação, a partir da mobilização dos veios já existentes.

Agradecimentos A dois revisores anônimos da RBG pelas sugestões ao original.

\section{Referências}

Barbosa A. L. M. 1969. Geologic map of the Ouro Preto, Mariana, Antônio P'ercira e São Bartolomeu quadrangles, Minas Gerais: Brazil. Washington, USGS/DNPM (Professional Paper, 641-A)

Brooks B. A. 1994. Fractal clustering of metamorphic veins: Comment, Geology, 22:11471148

Clarck M. B., Brantley S. L.. Fisher D. M. 1995. Power-law vein-thickness distributions and positive feedback in vein growth. Geology: 23:975-978.

Cavalcanti J.A.D. 1999. Mineralização aurífera de Lajes - Antonio Dias, Ouro Preto-MG. controle lito-estratigrático e estruturais. Instituto de Geociências, Universidade Estadual de Campinas, Campinas, Dissertação de mestrado, 108 p.

Corrêa Neto A. V., Dayan H. 1998. Deformation analysis on the central Rio das Velhas greenstone belt, Quadrilátero Ferrífero (MG). In: DEGEO/EM \& IBTA International Conference on Basement Tectonics, 14 ${ }^{\text {th }}$. Ouro Preto, MG., Abstracts, 128-130.

Dorr J.V.N. 1969. Physiographic, stratigraphic and structural development of the Quadrilatero Ferrifero, Minas Gerais, Brasil. Washington. USGS/DNPM, II0p. (Professional Paper, 64I-A)

Endo I. Fonseca M. A. 1992. Sistema de Cisalhamento Fundāo-Cambotas no Quadrilátero Ferrífero. MG: geometria e cinemática. In SBG/Núcleo MG. Simpósio de Geologia de Minas Gerais. 6. Semana de Estudos da SICEG, 30. Ouro Preto. Anais, 2831.

Endo I. 1997. Regimes tectônicos do Arqueano e Proterozóico no interior da placa sanfranciscana: Quadrilatero Ferrifero e areas adjacentes. $M G$. Instituto de Geociências, Universidade de São Paulo. São Paulo. Tese de Doutoramento. 24.3p.

Ferreira Fitho F: A. 1999. Análise estrutural qualitativa do Sistema de Fallhas Água Quente, borda leste do Quadrilátero Ferrifero-MG. Departamento de Geologia da Escola de Minas da Universidade Federal de Ouro Preto, Ouro Preto, Dissertação de Mestrado, $156 \mathrm{p}$

Hippertt J. F.. Massucato A. J. 1998. Phyllonitization and development of kilometer-size extension gashes in a continental-scale strike-slip shear zone, north Goiás, central Brazil. Journal of Structural Geolog!: 20:433-445.
Jébrak M. 1997. Fractal tectonic and gold deposit in the Abitibi greenstone belt. Short course. Universidade Estadual de Campinas (UNICANIP), maio de 1997.

Johnston J. D., McCalfrey K. J. W. 1996. Fractal geometries of vein systems and the variation of scaling relationships with mechanism. Journal of Structural Geology; 18:349-358.

Lacourt F. 1937. Jazidas auríferas de Ouro Preto e Mariana. Revista Mineração e Metalurgia. Julho-Agosto, pp. 90-93.

Mandelbrot B. B. 1983. The Fractal Geometry of Nature, New York/NY, W. H. Freeman. $461 p$.

Manning C. E. 1994. Fractal clustering of metamorphic veins. Geology, 22:335-338.

McCaffrey K. J. W., Johnston J. D. 1996. Fractal analysis of mineralised vein deposit: Curraghnalt gold deposit, County Tyrone. Mineralia Deposita, 31:52-58.

Nalini Jr. H.A. 1993. Análise estrutural descritiva e cinemática do flanco sul e terminaşäo periclinal do Anticlinal de Mariana e adjacências, regiäo sudeste do Quadrilátero Ferrifero, Minas Gerais, Brasil. Instituto de Geociências da Universidade Federal de Minas Gerais, Belo Horizonte, Dissertação de Mestrado, 132p.

Oliveira F. R. 1998. Contribuiģ̃oo ao estudo da geologia estrutural e da gênese do dépósito aurifero de Passagem de Mariana-MG. Instituto de Geociências da Universidade Estadual de Campinas, Campinas, Dissertação de Mestrado, 127p.

Passchier C. W.. Trouw R. A. J.. 1996. Microtectonics. Berlin, Springer Verlag, 289p.

Sanderson D. J.. Roberts S., Gumiel P. 1994. A fractal relationship between vein thickness and gold grade in drill core from La Cordosera, Spain. Economic Geolog!: 89: 168 173. 